مجلة أكاديمية شمال أوروبا المحكمة ـ الانمارك (الإصدار الأول) بتاريخ13/10/2018 $\mathbf{A}_{\mathrm{JNE}} \mathbf{A}^{-}$

\title{
Global warming phenomena it's harms and causes and previntations method
}

ظاهرة الاحتباس الحراري اضرارها واسبابها وطريقة الوقاية منها

\section{Prepared by}

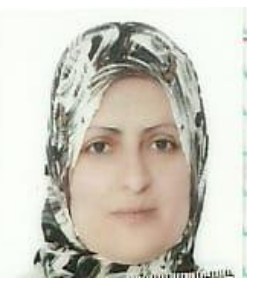

Dr.Eng. Lammiaa Abdul Rudah abd

Al-Isra University College

Baghdad - Iraq

dr.Lamiaa@esraa.edu.iq

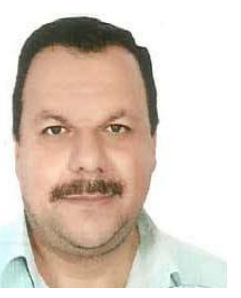

Eng. Mudafar Kadum Krady

Mudafar Engineering Consulting Office

Sultanate of Oman mudaferahmed@gmail.com 


\begin{abstract}
:
In this paper we study the global warming phenomena and its effect on the humanity on the earth and on the atmospheric, also we study its causes ,harms, and how to prevent it, we found that the progressing country have the great effect of causing this phenomena because of its industries and what's causes of it, also we found that the main causes of the global warming was the green house gases effect, we find that we could reduced or prevent the global warming by encourage the agricultural of wide land of some kind of pants on the earth, and use clean fuel, or renewable energy sources by the glob to save the life on the earth .
\end{abstract}

Key words: Global warming phenomena - harms - preventions method.

\title{
1.1Introduction
}

We try to understand the changed of the weathers happened at world so we study this global phenomena of warming which refer to rabid increasing in temperature of the atmospheric air at summer seasons specially and another seasons too around the world with many climatic changed all over the globe, the global warming is a phenomenon where it causes a rise in the average temperature of the Earth's atmosphere and water bodies since the latest century and is still in progress, then we try to find the global solution that reduced or prevent this phenomena where , Since the early 1900's, Earth's average surface temperature has rise by about 0.8 ${ }^{\circ} \mathrm{C}\left(1.4{ }^{\circ} \mathrm{F}\right)$, with almost two-thirds of this rate occurring since 1980 ( 1).

Also we study the effects of global warming on the human kind, plants and animals in numbers of ways. This effects, increase ocean levels, droughts and changed weather patterns. It is well recognized by scientists around the world as a serious public health and environmental concern.

According to NASA, in 2016 the Earth's surface temperature shattered the previous record for hottest year by $0.12^{\circ} \mathrm{C}$. That record was set in 2015 , which broke the previous record by $0.13^{\circ} \mathrm{C}$. That record had been set in 2014.(2)

The Union of Concerned Scientists divided the effects of global warming in five categories: people, freshwater, oceans, ecosystems and temperature.(3 )

1.2 Review of this case : Suggestions policy responses to global warming include mitigation through emissions reduction, adaptation to its effects etc. Most of the countries in the world are members of the United Nations Frame work Convention on Climate Change(UNFCCC) whose see that objective is to prevent dangerous anthropocentric i.e., human-induced climate change. All of the party members have taken an oath to adopt a range of policies that work around reducing greenhouse gas emissions that are the whole reason for an increase in global. Currently efforts as of the early 21 st century that are mainly directed towards reducing emissions seem to be quite inadequate to cope up with the UNFCCC's $2{ }^{\circ} \mathrm{C}$ targets.(4)

$1.3 \mathrm{~A}$ common view is that the current global warming rate will Continue or accelerate. But we argue that rapid warming in recent decades has been driven mainly by non- $\mathrm{CO} 2$ greenhouse gases also (GHGs), such as chlorofluorocarbons, $\mathrm{CH} 4$, and $\mathrm{N} 2 \mathrm{O}$, not by the products of fossil fuel burning, $\mathrm{CO} 2$ and aerosols, the positive and negative climate forcing's of which are partially 
offsetting. The growth rate of non-CO2 GHGs has declined in the past decade. If sources of CH4 and $\mathrm{O} 3$ precursors were reduced in the future, the change in climate forcing by non-CO2 GHGs in the next 50 years could be near zero. Combined with a reduction of black carbon emissions and plausible success in slowing $\mathrm{CO} 2$ emissions, this

Reduction of non-CO2 GHGs could lead to a decline in the rate of global warming, reducing the danger of dramatic climate change.

Such a focus on air pollution has practical benefits that unite the interests of developed and developing countries. However, assessment of ongoing and future climate change requires composition specific long-term global monitoring of aerosol properties.

As we see in figure (1) Global Carbon Cycle (Billion Metric Tons Carbon) Which GHGs cause a global climate forcing, i.e., an imposed perturbation of the Earth's energy balance with space (5). There are many competing natural and anthropogenic climate forcing's, but increasing GHGs are estimated to be the largest forcing and to result in a net positive forcing, especially during the past few decades $(4,6)$.

Evidence supporting this interpretation is provided by observed heat storage in the ocean (7), which is positive and of the magnitude of the energy imbalance estimated from climate forcing's for recent decades (8).

The Intergovernmental Panel on Climate Change (IPCC) (4)

Figure (1) Global Carbone Cycle (Billion Matric Tons Carbone)

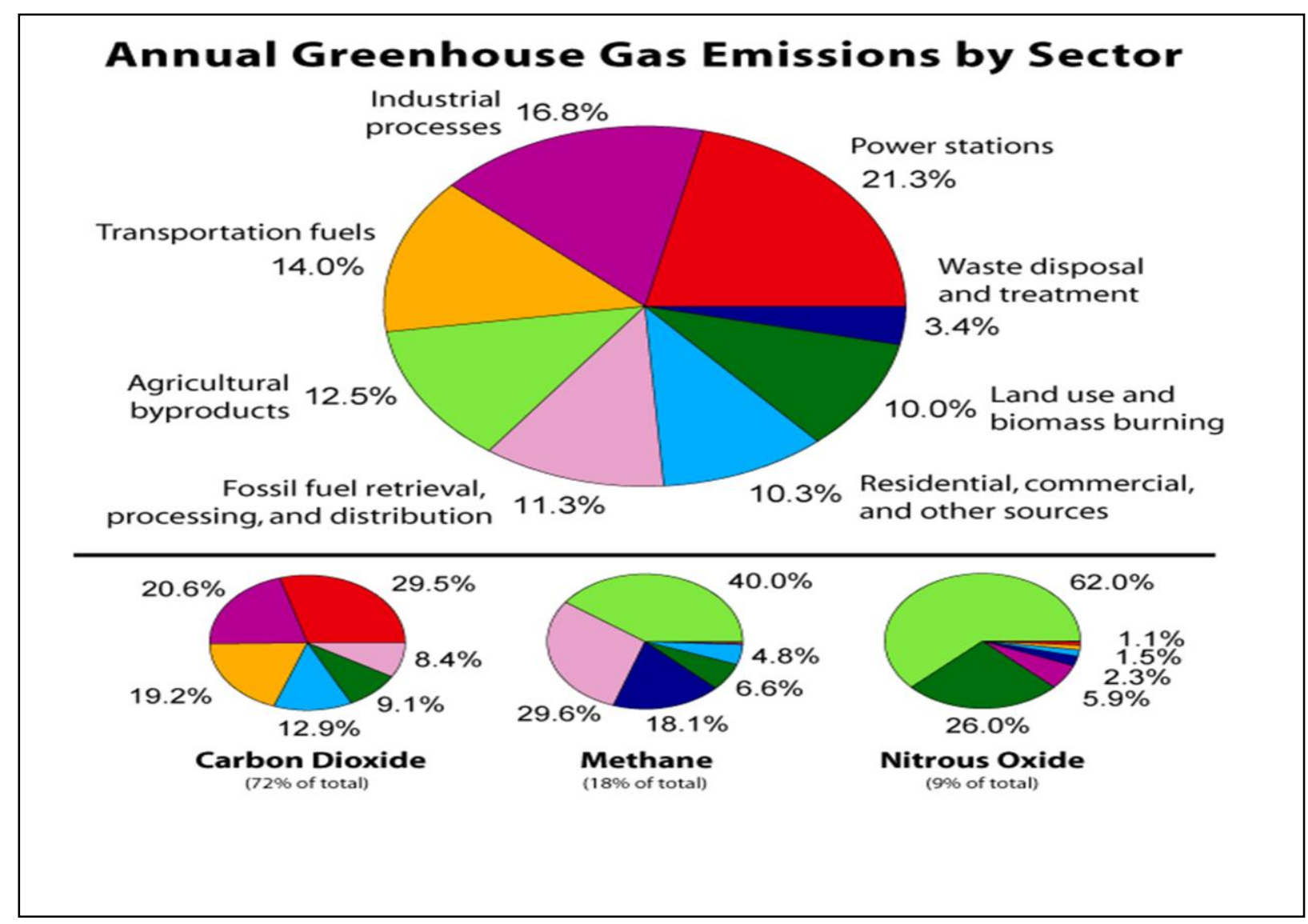


has considered a range of cases for future GHGs, which is further expanded in its

1.4 Special Report on Emissions rate (9).as shown in fig.(2)Yet global warming simulations have focused on "business as usual' state with rapidly increasing GHGs. These case .yield a steep, relentless increase in global temperature throughout the twenty-first century $(4,10)$ with warming of several degrees Celsius by 2100 , if climate sensitivity is $2-4^{\circ} \mathrm{C}$ for doubled $\mathrm{CO} 2$, as climate models suggest $(4,11-13)$. These figures can give though that curtailment of global warming is almost hopeless. The 1997 Kyoto Protocol, which calls for industrialized nations to reduce their CO2 emissions to $95 \%$ of 1990 levels by 2012 (14), is itself considered a difficult target to achieve. Yet the climate simulations lead to the conclusion that the Kyoto reductions will have little effect in the twenty-first century (15), and "Kyoto's" may be needed to reduce warming to an acceptable level (16)

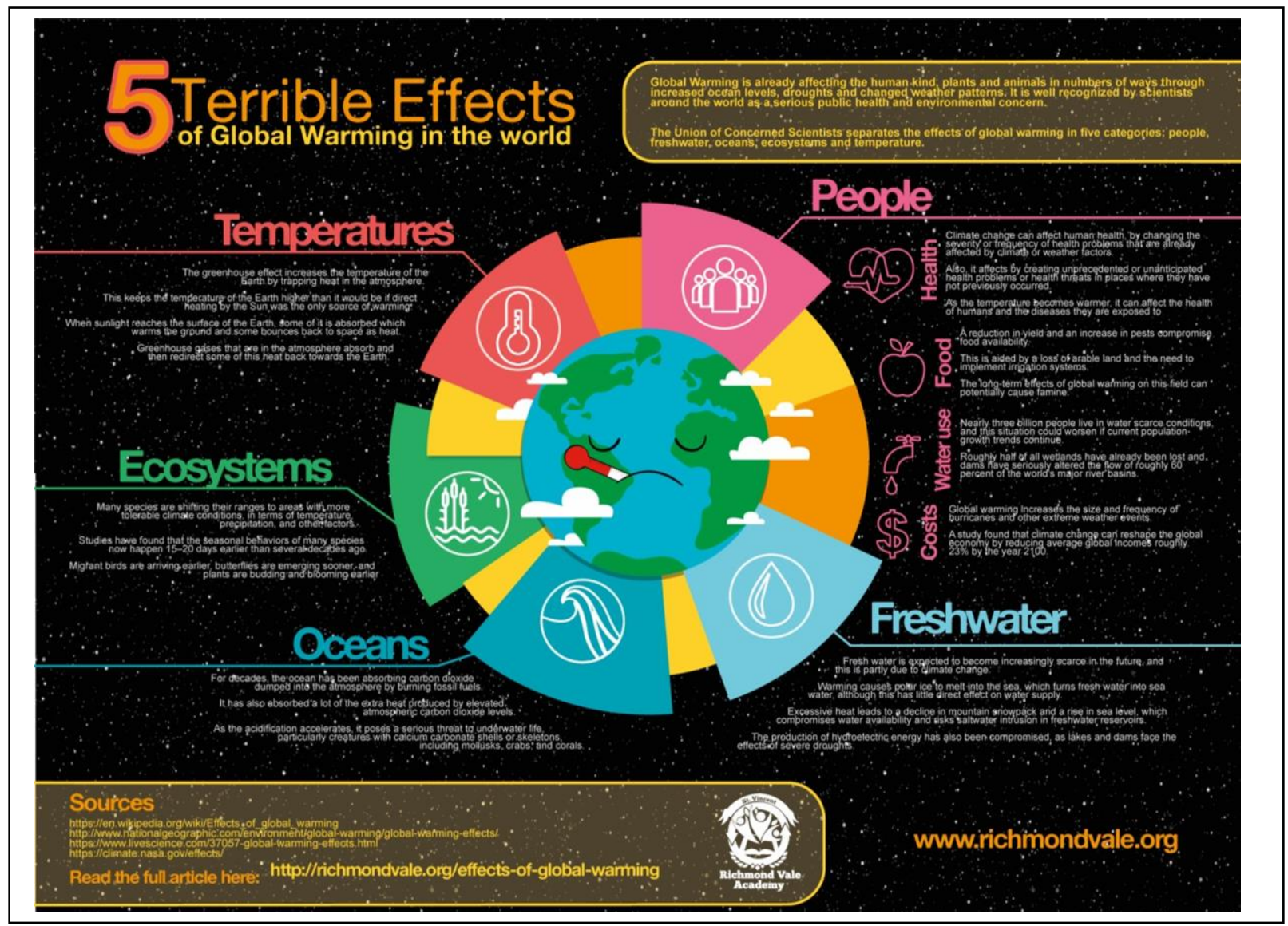

Figure (2) show the effect of global warming all over the world as sources

\subsection{Climate Forcings in the Industrial:}

Fig. 3 shows graphs of estimated climate forcing's since 1850, which are similar to previous presentations $(4,6)$. Forcing's for specific GHGs differ by as much as several percent from

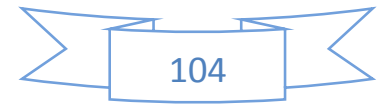


values we estimated earlier: CO2 (21\%), CH4 (12\%), N2O (23\%), chlorofluorocarbon 11 (CFC11) $(16 \%)$, and CFC-12 (18\%). Our prior results, used by the IPCC (4), were analytic fits to calculations with a one-dimensional radiative-convective model (17). The present results (Table 1) are based on calculations of

Adjusted radiative forcing (5), using the SI2000 version of the Goddard Institute for Space Studies three-dimensional climate model $(8,13)$, with the absorption coefficients fit to line-byline radiative transfer calculations, using current HITRAN (18) absorption line data. Thus the present results are improved in several ways.

Estimated Forcings:

We separate $\mathrm{CO} 2, \mathrm{CH} 4$, and $\mathrm{CFCs}$ in Fig 3 because they are produced by different processes and have different growth rates. We associate with $\mathrm{CH} 4$ its indirect effects on troposphere $\mathrm{O} 3$ and stratospheric $\mathrm{H} 2 \mathrm{O}$ to make clear the importance of $\mathrm{CH} 4$ as a climate forcing. We assume that one-fourth of the $0.4 \mathrm{Wym} 2$ climates forcing due to increasing Troposphere $\mathrm{O} 3$ is caused by increasing $\mathrm{CH} 4$ (chapter 2 in ref. 4; ref. 19). We calculate an indirect effect of $0.1 \mathrm{Wym} 2$ for $\mathrm{CH} 4$ oxidized to $\mathrm{H} 2 \mathrm{O}$ in the stratosphere (20). The recent trend of stratospheric $\mathrm{H} 2 \mathrm{O}(20,21)$ is even larger than $\mathrm{CH} 4$ could cause but part of the observed trend may be a result of transport from the troposphere.

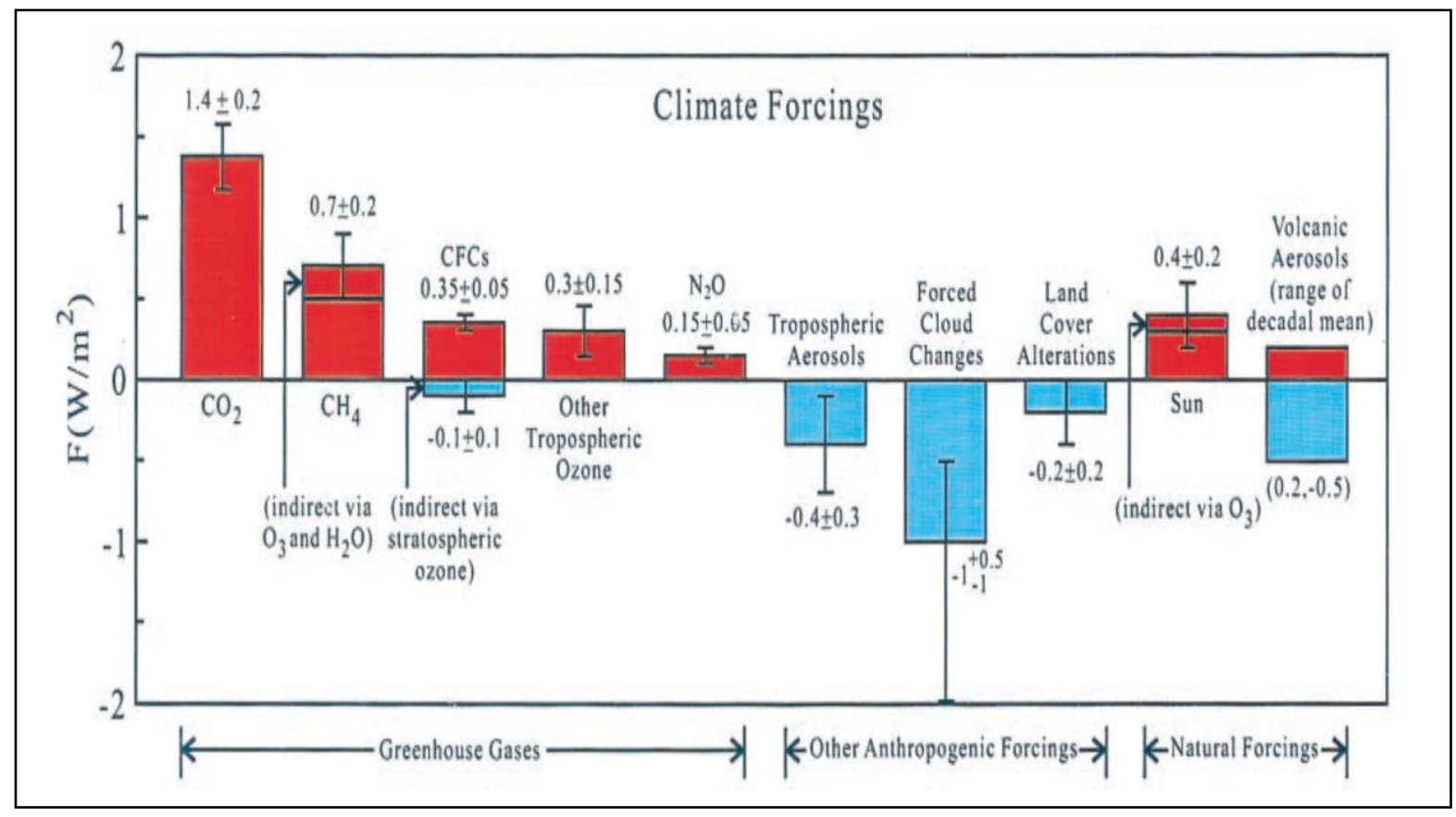

\section{The greenhouse gases (GHGs) Rates:}

Atmospheric amounts of green house gases is the principal human-influenced of it which have been monitored in recent years and extracted for earliertimes from bubbles of air trapped in polar ice sheets (37). Gases that cause the largest climate forcings, $\mathrm{CO} 2$ and $\mathrm{CH} 4$, are showing Fig. 4. IPCC IS92 scenarios (chapter 2 in ref. 4) for the next 50 years are also shown in Fig. 4. IS92a, at least so far, has been the most popular scenario for climate model simulations. These climate forcing projections involve many assumptions and are very uncertain.

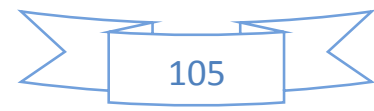




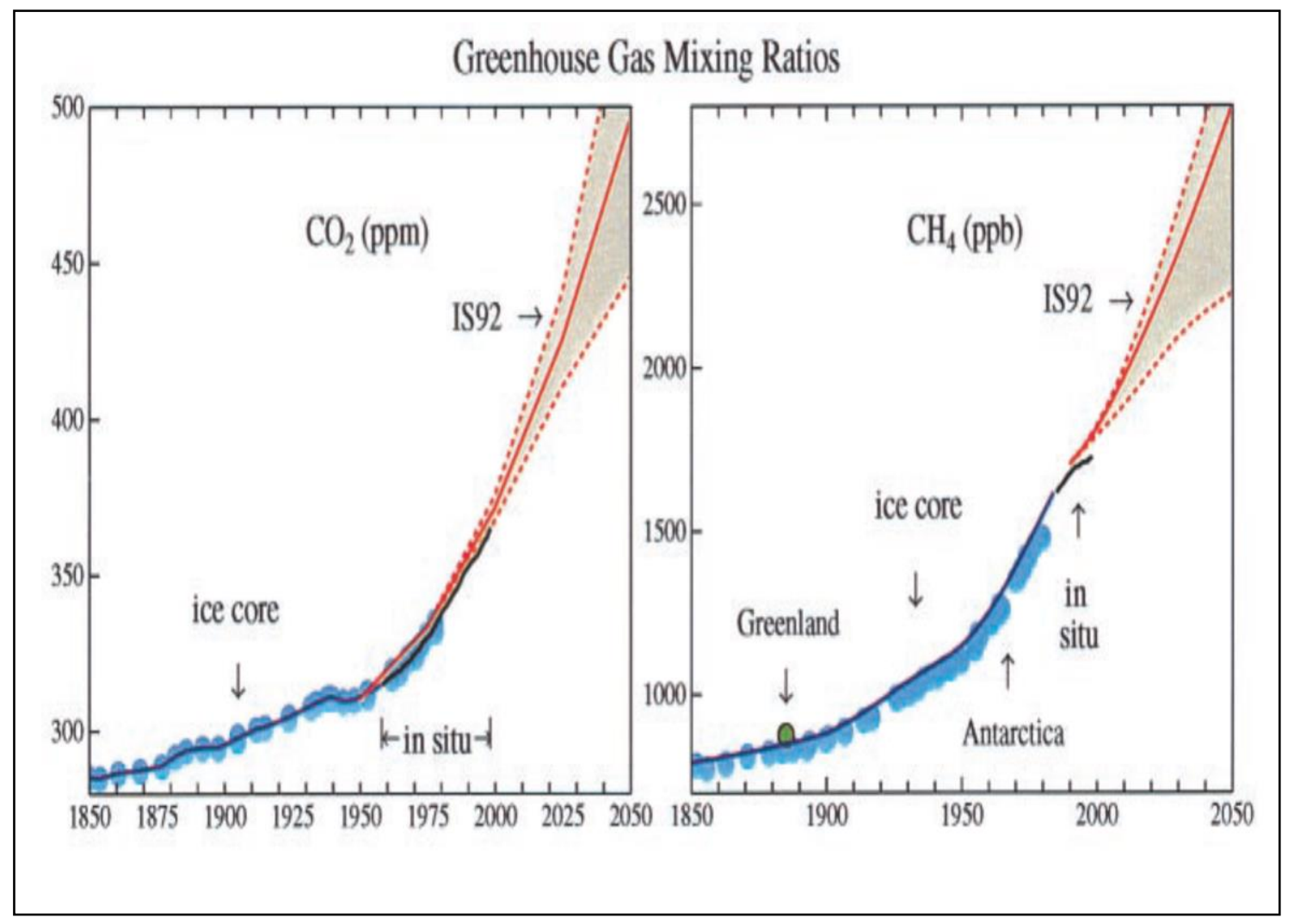

Figure (4) Atmospheric $\mathrm{CO} 2$ and $\mathrm{CH} 4$ observations and range of IS92 cases (the solid red line is IS92a).

GHGs, including CFCs, was already a $15 \%$ reduction from the principal 1990 IPCC case 18). The observed increase inCH4 in the 1990s falls below the lowest IS92 case, whereas CO2 falls on the lowest IS92 case .

Trends of the climate forcings are revealed better by their annual growth rates, as shown in Fig. 5 for anthropogenic GHGs.

The forcings are calculated from the equations of Table 1. The CO2 and CH4 amounts for 1999 were kindly provided by Ed Dlugokencky and Tom Conway of the National Oceanic and Atmospheric Administration Climate Monitoring and Diagnostics Laboratory. The estimated negative forcing due to stratospheric O3 depletion, 20.1Wym2, is smaller than the 20.2Wym2 that we used earlier (6) because of changes in the vertical profile of O3depletion estimated from observations. $\mathrm{O}_{3}$ trends recommended by the World Meteorological Organization (22) have less depletion in the tropopause region (where $\mathrm{O}_{3}$ loss causes surface cooling) and greater loss in the middle stratosphere (where $\mathrm{O}_{3}$ loss causes surface warming) compared with the $\mathrm{O} 3$ changes that we used previously $(5,6)$. Climate forcing by $\mathrm{CO} 2$ is the largest forcing, but it does not dwarf the others (Fig. 1). Forcing by $\mathrm{CH} 4(0.7 \mathrm{Wym} 2)$ is half as large as that of $\mathrm{CO} 2$, and the total forcing by non-CO2 GHGs (1.4Wym2) equals that of $\mathrm{CO} 2$. Moreover, in comp due to different activities, we must note that fuels producing most of the $\mathrm{CO} 2$ are also the main source of aerosols; especially sulfates, black carbon, and organic aerosols (4, 13).As shown in fig (6)

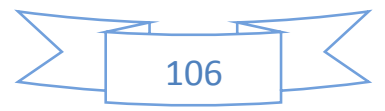


Fossil fuels contribute only a minor part of the non-CO2 GHG growth via emissions that are not essential to energy production forcings.
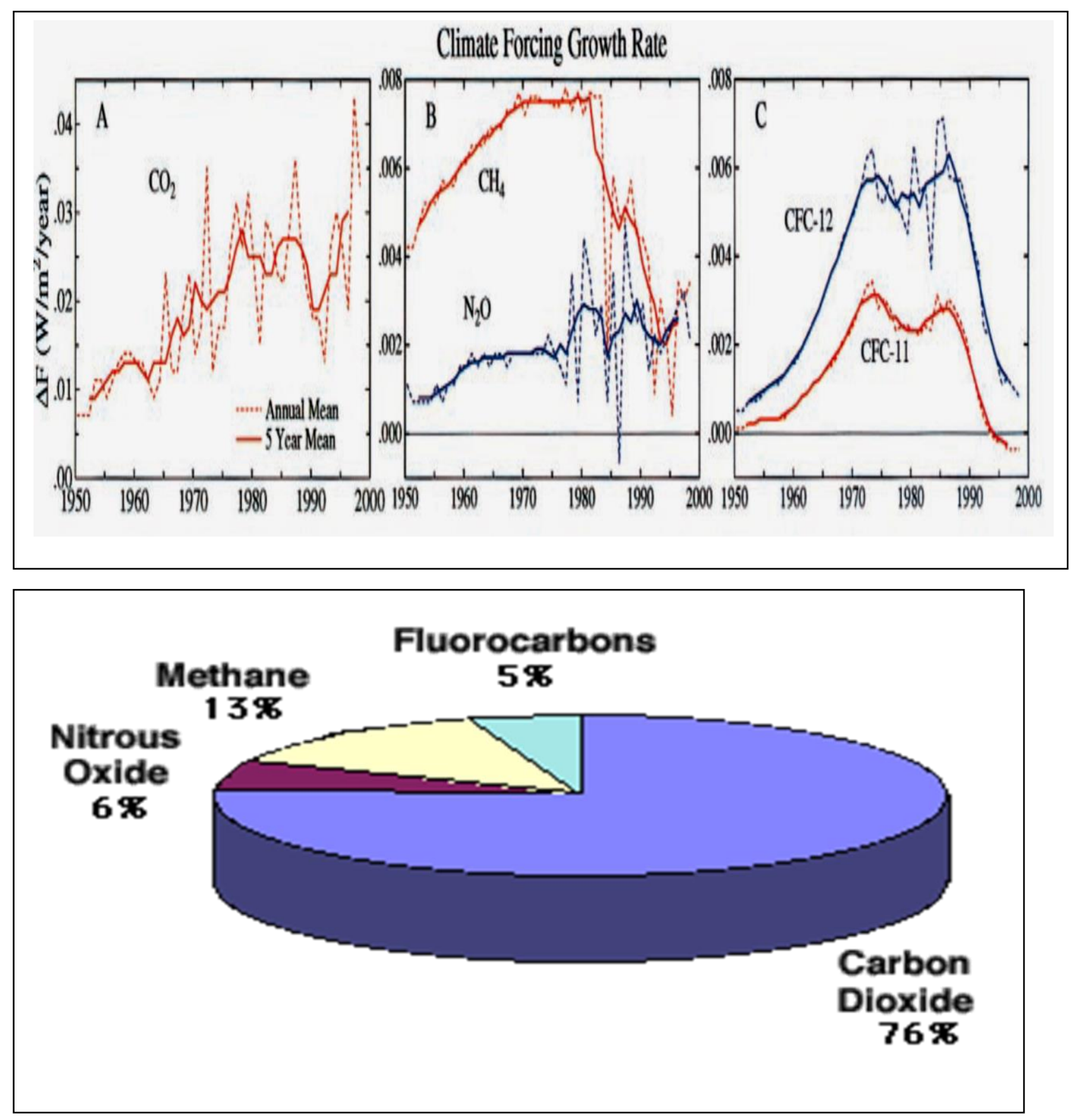

Figure 6 shows the distribution of GHG in Earth's atmosphere

We know that According to a paper published in Nature takes on the ambitious task of connecting micro- and macro-level estimates of climate costs. The study finds that climate change can reshape the global economy by reducing average global incomes roughly 23 percent

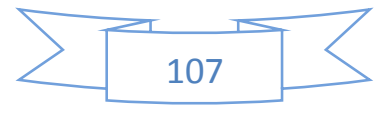


by the year 2100. This study presents the first evidence that economic activity in all regions is coupled in some way to global climate. The study also sets up a new empirical diagram for modeling economic loss in response to climate change.as we seen in fig. (7) \&fig. (8) The main sources of GHGs are produced by some countries where they produced a progress at technology all over the world also they give us the pollution too .
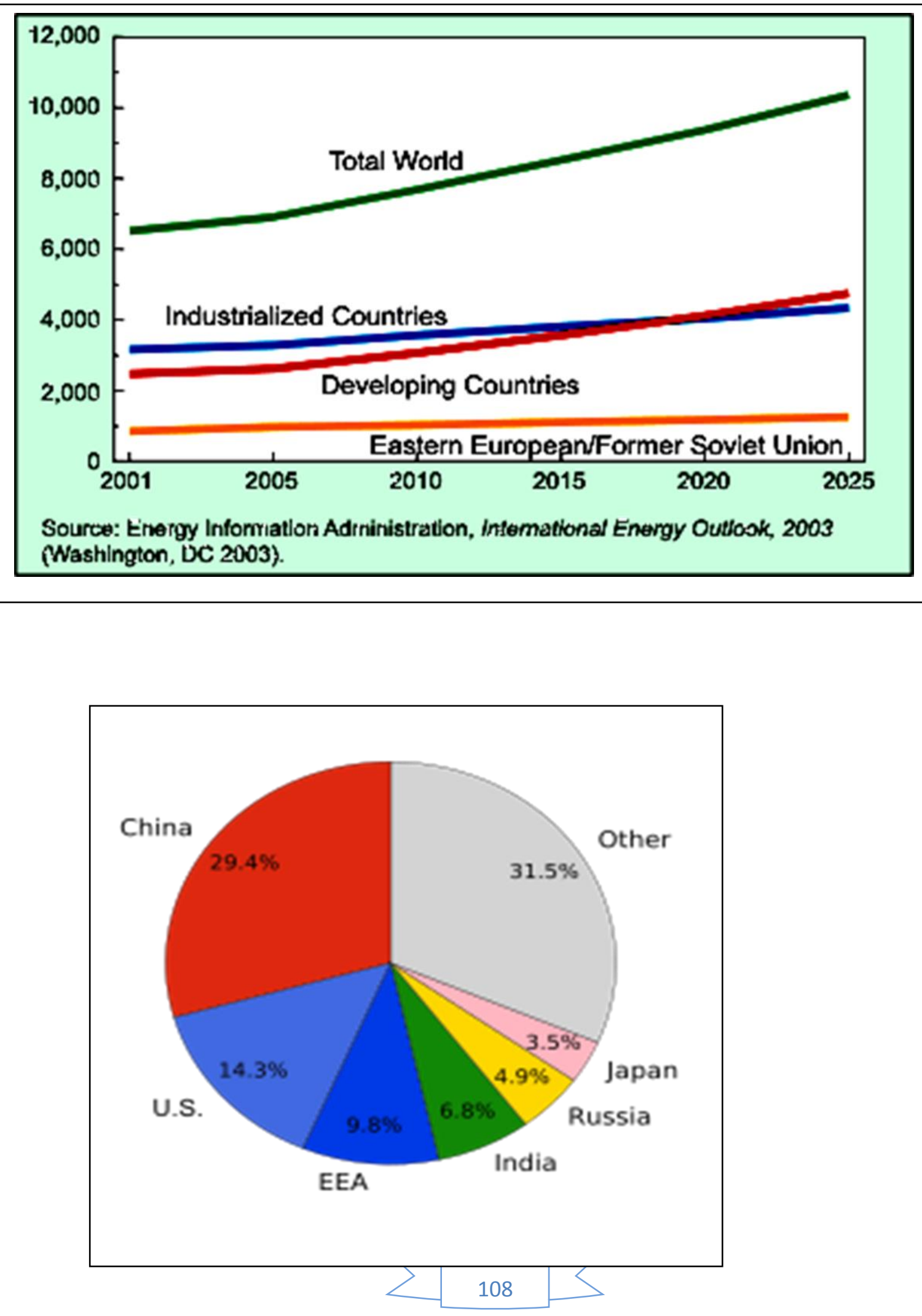
figure (8) show the statistical drawing of the carbon dioxide produced all over the world

Also the Public reactions of global warming and concern about its effects are also increasing. A global 2015 Pew Research Center report showed that a median of 54\% of all respondents asked consider it "a very serious problem". Significant regional differences exist, with Americans and Chinese (whose economies are responsible for the greatest annual $\mathrm{CO}_{2}$ emissions) among the least concerned. ${ }^{[23]}$ as shown in figure (9) the increasing of carbon dioxide concentration as measured at Mauna ,Hawaii .we can see the rapid increasing of carbon dioxide every decades

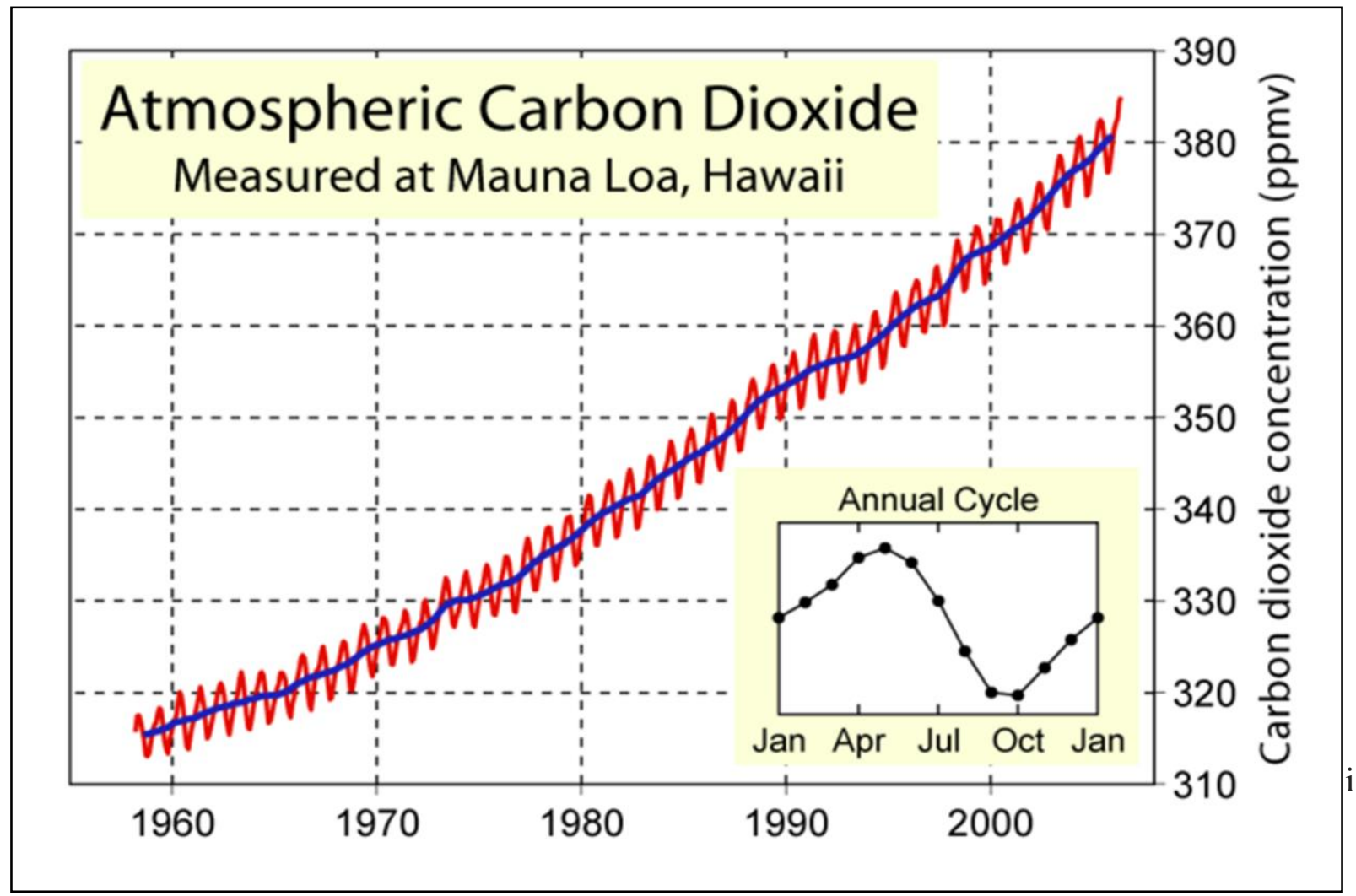

The main older source of global warming was the mean $\mathrm{CO} 2$ concentration . Which growth rate in the next 50 years to be about the same as in the past two decades. The additional forcing in 50 years is about $1 \mathrm{Wym} 2$ for

An average annual $\mathrm{CO} 2$ increment of $1.5 \mathrm{ppm}$.

Is such a $\mathrm{CO} 2$ growth rate scared us? We note that the $\mathrm{CO} 2$ growth rate increased little in the past 20 years, while much of the developing world had rapid economic growth. The United States also had strong growth with little emphasis on energy efficiency, indeed with increasing use of energy-inefficient sports

utility machines. This fact suggests that there are necessaries to achieve reduced emissions consistent with strong economic growth. Limiting CO2 growth to $75 \mathrm{ppm}$ in the next 50 years

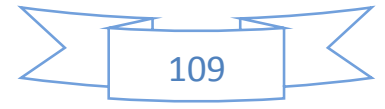


probably requires a moderate decrease in $\mathrm{CO} 2$ emission rates, as continuation of high terrestrial sequestration of $\mathrm{CO} 2$ is uncertain.as we shown in figure (10) according to the carbon dioxide analysis center

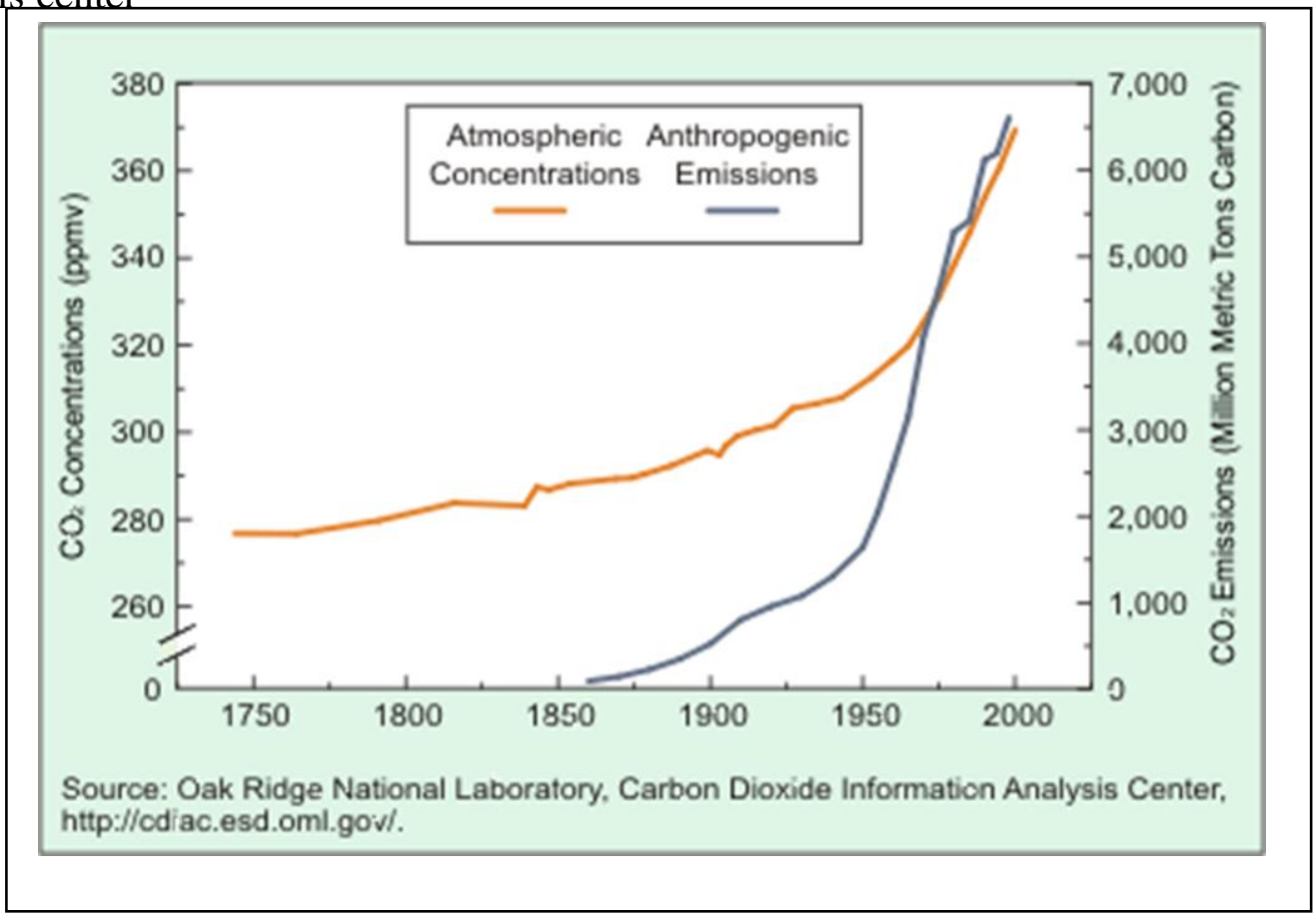

In the near term (2000-2025) this state can be achieved by improved energy efficiency and a continued trend toward decarburization of energy sources, e.g., increased use of gas instead of coal.

Technologies for improved efficiency exist (25), and implementation can be driven by economic self-interest, but governments need to remove barriers that discourage buying of energy efficiency (15). Business- as-usual cases often understate a long-term trend toward decarburization of the energy supply (figure 8 in ref. 4), but the IPCC Special Report on Emission state (9) includes a subset that is consistent with our $\mathrm{CO} 2$ cases.

Many studies show that the temperature of the periods between 2010 to 2018 was hotter than any other decade in at least the past 1,300 years. This warming is altering the earth's climate system, including its land, atmosphere, oceans, and ice, in far-reaching ways. So we have to be clear to solve this case to preventing any any progressing of the pavilion or global warming phenomena

In 2013, the Intergovernmental Panel on Climate Change(1) (IPCC) Fifth Assessment Report concluded, "It is extremely likely that human influence has been the dominant cause of the observed warming since the mid-20th century." ${ }^{[5]}$ The largest human influence has been the emission of greenhouse gases such as carbon dioxide, methane, and nitrous oxide.

Climate model projections summarized in the report indicated that during the 21 st century, the global surface temperature is likely to rise a further 0.3 to $1.7^{\circ} \mathrm{C}\left(0.5\right.$ to $\left.3.1^{\circ} \mathrm{F}\right)$ in the lowest emissions scenario, and 2.6 to $4.8^{\circ} \mathrm{C}\left(4.7\right.$ to $\left.8.6^{\circ} \mathrm{F}\right)$ in the highest emissions

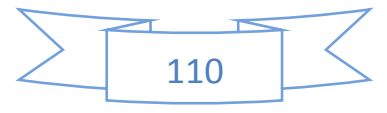


scenario. ${ }^{[6]}$ These findings have been recognized by the national science academies of the major industrialized nations (17) and are not disputed by any scientific body of national or international standing. ${ }^{[9][10]}$

Future climate change and associated impacts will differ from region to region $(11,12)$ Anticipated effects include increasing global temperatures, rising sea levels, changing precipitation, and expansion of deserts in the subtropics. ${ }^{[13]}$ Warming is expected to be greater over land than over the oceans and greatest in the Arctic, with the continuing retreat of glaciers, permafrost, and sea ice. Other likely changes include more frequent extreme weather events such as heat waves, droughts, heavy rainfall with floods, and heavy snowfall ${ }^{[14]}$ ocean acidification; and species extinctions due to shifting temperature regimes.

Effects significant to humans include the threat to food security from decreasing crop yields and the abandonment of populated areas due to rising sea levels $(15,16)$ Because the climate system has a large "inertia" and greenhouse gases will remain in the atmosphere for a long time, many of these effects will persist for not only decades or centuries, but for tens of thousands of years (20)to come as we see at figure (11) the annual mean increasing in temperature or Global mean surface-temperature change from 1880 to 2017.

It's clear that the mean temperature is rise and still rise until this moment.

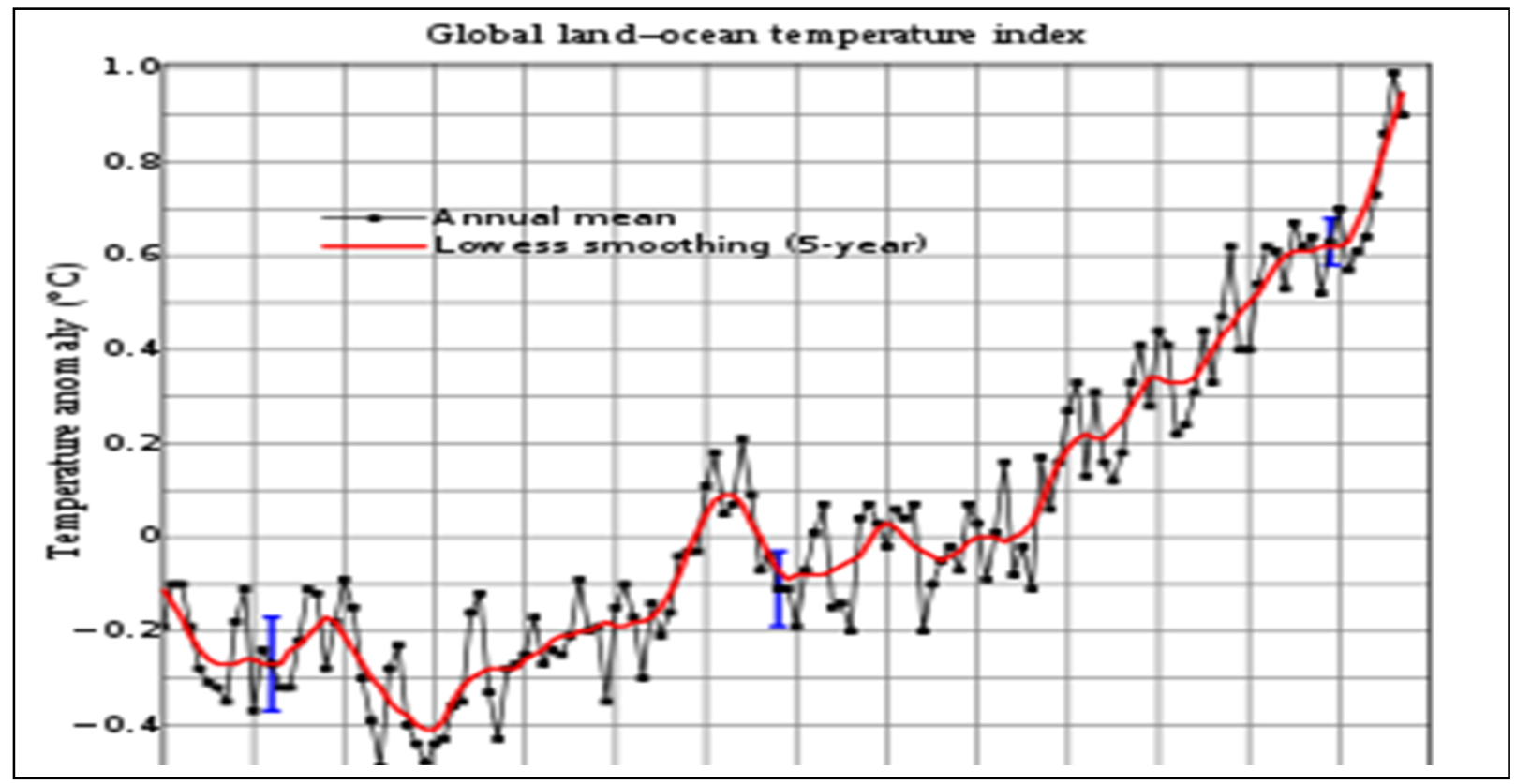

At this research we try to explain the way that we could do to prevent the global warming from expanded and increasing rapidly later.

After we explain this phenomena where we called it as a phenomena, because it's touch our lives on this planet, so we show the risk of it as shown in figure (12) the future increasing in temperature due to the global warming case since (1990) until (2100) . 


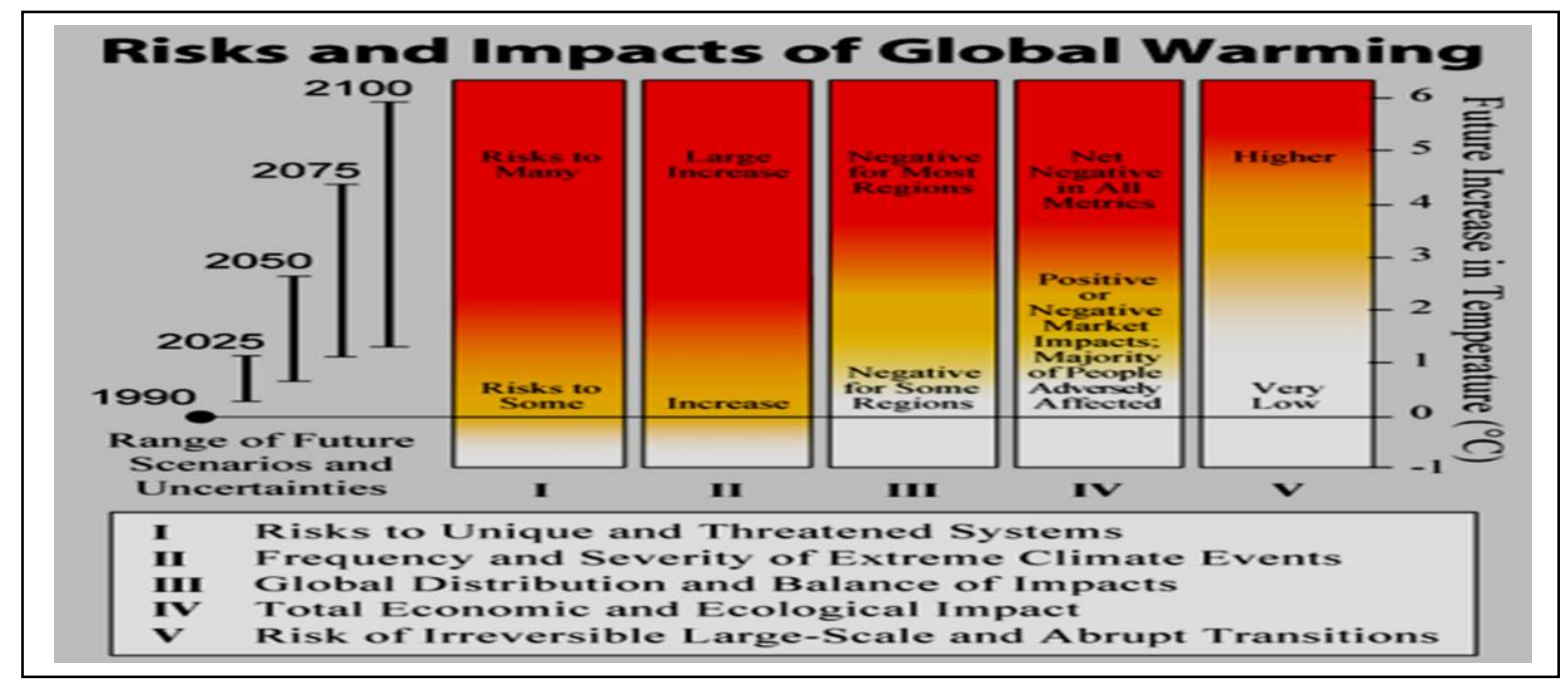

The way we thought that could prevent or reduced the global warming are:

1. Use a large amount of the solar energy that causes the global warming, all over the globe, so the received solar ray is equal to that emission and trapped at the atmospheric air.

2: Reduce the green house gases by agricultural much land with trees and plants that give large amounts of oxygen and absorbed many tons of $\mathrm{CO}_{2}$, to give balance of the environment.

3. Use the clean Energy for the industrial, or use the renewable energy.

4. Use the renewable energy for transport also like produced cars or vehicle working with water or using solar energy.

5. Use the energy of natural phenomena like volcano, storms, and Hurricanes to produced useful energy to use at many sector of life at all countries.

Recommends: Apply and study the solutions in this paper rapidly and apply the solutions all over the world to solve this problem, and find another solutions to this phenomena, finally use the power of the global warming to help the humanity.

\section{Reference:}

1. Richmond Vale June 19, 2017 Climate Compliance Conference (5 Effects of Global Warming).

2. Hitchhiking from Georgetown down to Kingstown by Karolina_ ( 5 Awesome ideas for reusing and recycling water) .

3. Wigley, T. M. L. (1998) Geophys. Res. Lett. 25, 2285-2288.

4. Intergovernmental Panel on Climate Change (1996) Climate Change 1995, eds. Houghton

5.J. T., Meira Filho, L. G., Callander, B. A., Harris, N., Kattenberg, A. \& Maskell, K 
(Cambridge Univ. Press, Cambridge, U.K.). ),pp. 127-164. 5. Hansen, J., Sato, M. \& Ruedy, R. (1997) J. Geophys. Res. 102, 6831-6864.

6. Hansen, J., Sato, M., Lacis, A., Ruedy, R., Tegen, I. \&Matthews, E. (1998) Proc. Natl. Acad. Sci. USA 95, 12753-12758.

7. Levitus, S., Antonov, J. I., Boyer, T. P. \& Stephens, C. (2000) Science 287, 2225-2229.

8. Hansen, J., Sato, M., Ruedy, R., Lacis, A., Asamoah, K., Beckford, K., Borenstein, S., Brown, E., Cairns, B., Carlson, B., et al. (1997) J. Geophys. Res. 102, 25679-25720.

9. Nakicenovic, N., Davidson, O., Davis, G., Grubler, A., Kram, T., La Rovere, E. L., Metz, B., Morita, T., Pepper, W., Pitcher, H., et al. (2000) Special Report on Emissions Scenarios (Cambridge Univ. Press, Cambridge, U.K.).

10. Suplee, C. \& Pinneo, J. B. (1998) Natl. Geogr. 193, 38-71.

11. Manabe, S. \& Wetherald, R. (1975) J. Atmos. Sci. 32, 3-15.

12. Charney, J. (1979) Carbon Dioxide and Climate (Natl. Acad. Press, Washington, DC).

13. Hansen, J., Ruedy, R., Lacis, A., Sato, M., Nazarenko, L., Tausnev, N., Tegen, I. \& Koch,

D. (2000) in General Circulation Model Development, ed. Randall, D. (Academic, New York

14. Bolin, B. (1998) Science 279, 330-331.

15. Internet source, Wikipedia. Org

16. Malakoff, D. (1997) Science 278, 2048.

17. Hansen, J., Fung, I., Lacis, A., Rind, D., Lebedeff, S., Ruedy, R., Russell

18. Rothman, L., Rinsland, C., Goldman, A., Massie, S., Edwards, D., Flaud, J., Perrin, A.,

Camy-Peyret, C., Dana, V., Mandin, J., et al. (1998) J. Quan. Spec. Rad. Trans. 60, 665-710.

19. Lelieveld, J., Crutzen, P. J. \& Dentener, F. J. (1998) Tellus 50B, 128-150.

20. Shindell, D. (2000) Geophys. Res. Lett., in press.

21. Forster, P. M. de F. \& Shine, K. P. (1999) Geophys. Res. Lett. 26, 3309-3312.

22. World Meteorological Organization (1999) Scientific Assessment of Ozone Depletion: Global

Ozone Research and Monitoring Project, Report 44 (World Meteorological Organization,Geneva).

23. Andreae, M. (1995) in World Survey of Climatology, ed. Henderson-Sellers, A. (Elsevier,Amsterdam), Vol. 16, pp. 347-398.

24. Twomey, S. A. (1991) Atmos. Environ. 25A, 2435-2442.

25. Albrecht, B. A. (1989) Science 245, 1227-1230. 